\title{
Adoption of Improved Agricultural Technologies in Developing Countries: Literature Review
}

\author{
Solomon Yokamo \\ Arbaminch Agricultural Research Center, Ethiopia.
}

\begin{abstract}
How to cite this paper: Solomon Yokamo. (2020) Adoption of Improved Agricultural Technologies in Developing Countries: Literature Review. International Journal of the Science of Food and Agriculture, 4(2), 183-190.

DOI: $10.26855 /$ ijfsa.2020.06.010
\end{abstract}

Received: April 9, 2020

Accepted: May 15, 2020

Published: June 1, 2020

*Corresponding author: Solomon Yokamo, Arbaminch Agricultural Research Center, Ethiopia.

Email: solomonyokamon@gmail.com

\begin{abstract}
Adoption of improved agricultural technologies is the tool for boosting production and productivity of agricultural sector, poverty reduction and ensuring food security in developing countries. Due to a plenty of determining factors in most developing countries, the rate and intensity of adoption of improved agricultural technologies is still low. This study focuses on some potential factors hindering farmers from adopting and using of improved agricultural technologies in developing countries. Many literatures were reviewed and found that economical, technological, socio-cultural, demographic and institutional factors are the main determinant factors in technology adoption and diffusion. In order to increase the likelihood of adoption of the improved agricultural technologies by farmers, policy makers should focus on building irrigation scheme, strengthening research-extension-farmers (R-E-F) linkage, making credit services more accessible without bias, equipping development agents with different training and workshops, empowering educational sector to focus on adult teaching, advising farmers to improve their educational level and making information accessible to farmers on time and finally the technology developer should incorporate the need and perceptions of farmers during technology design and development; will enhance the adoption of the technology more easily.
\end{abstract}

Keywords

Adoption, Diffusion, Agricultural technology, Farmers research group

\section{Introduction}

Agriculture is the foundation for many developing countries. The vast majority of the world's poor lives in rural areas and engaged in agriculture. It is the base for supply of basic human needs, as it is the baseline for food security ${ }^{1}$, for industrial growth and to different areas both directly and indirectly. It plays an important role in reduction of poverty, economic growth, enhancing food security and rural development. Smallholder agriculture dominates the sector. Smallholder agriculture is identified as a vital development tool for achieving millennium development goals, one of which is to halve the people suffering from extreme poverty and hunger by 2015 [1, 2]. However, majority of smallholder farmers relies on traditional methods of production and this has lowered the level of productivity. For instance, over $70 \%$ of the maize production in the majority of developing countries is from smallholders who use traditional methods of production [3]. The yield that the farmers obtained is very low due to average farmer uses local cultivars which has low yield potential, most of the maize grown is under rain-fed conditions, irrigation is used only in

\footnotetext{
${ }^{1}$ Food Security means that all people at all times have physical \& economic access to adequate amounts of nutritious, safe, and culturally appropriate foods, which are produced in an environmentally sustainable and socially just manner, and that people are able to make informed decisions about their food choices.
} 
limited areas, very limited use of chemical fertilizers and pest control is not adequate [3]. This points direction to policy makers how to design and plan different strategy to increase production and productivity through using advanced and farmer-friendly technologies.

The importance of agricultural technology adoption in ending poverty and food insecurity were well discussed by [3, 4, 5, 6, 7, 8, 9]. In developing countries, improving the livelihoods of rural farm households through agricultural productivity would remain a mere wish if agricultural technology adoption rate is low. Hence, there is a need to adopt the proven agricultural technologies so as to heighten production as well as productivity and thereby the living condition of the rural poor. Since the need of the rapidly growing population could not be meet by expanding the area under cultivation, developing, employing and disseminating yield increasing agricultural technologies is imperative [10]. Technology adopter farmers increase productions, leading to constant social and economic development. Adoption of improved agricultural technologies has been associated with higher income and lower poverty, improved nutritional status, lower staple food prices, increased employment opportunities as well as earnings for landless laborers [11].

According to [12], in the main factors for the success of green revolution in Asian countries; adoption of improved technologies was the foremost factors. According to [13], traditionally, agricultural technology adoption decision was seriously been determined by imperfect information, risk, uncertainty, institutional constraints, human capital, input availability and infrastructural problems. To bring remedy for such challenges, Sasakawa Global 2000 (SG-2000) program is been in place and intended to work with smallholder farmers and their respective agriculture ministry's so as to increase agricultural production and productivity by employing agricultural technologies that could best keep soil fertility. The program has put farmers as the forerunners and drivers in adopting agricultural technologies and promotion of agricultural intensification.

Many studies have been conducted on innovation and adoption of new technologies and the impact of adopting new technology in developing countries. However, new agricultural technologies are often adopted slowly and several aspects of adoption remain poorly understood despite being seen as an important route out of poverty in most of the developing countries $[14,15]$. This paper tries to review different scholarly literature done on adoption of new agricultural technology and factors that are responsible for slow rate of improved technology adoption in developing countries.

\section{Agricultural technology adoption}

The adoption of improved agricultural technologies is very important means for poverty alleviation and to bring assure food security in developing country. Farmers cannot easily adopt agricultural improved technology due to different factors and incase the adoption level is going slowly and many aspects of adoption is not well understood. There are a lot of scholarly literature reports on a number of constraints to adoption, such as the nature of the technology, awareness about the technologies, risk aversion, institutional constraints, lack of human and financial capital and lack of infrastructure. Adoption and diffusion theory have been widely used to identify the determining constraints that influence the decision of the user whether to adopt the innovation or to reject it. Innovation is an idea, practice or object that is perceived as new by an individual [16]. Making a decision about a particular innovation goes through five steps, which are called the innovation diffusion theory (IDT). The first stage is when the individual gets to know the innovation and how a new technology functions, its purpose and the need for it. The second stage occurs when the individual likes or dislikes this new technology. There are five attributes that encourage an individual to like a new technology and affect their decision as [16] identified.

1) Relative advantage: answers "is the new technology is better than existing technology?",

2) Compatibility: the degree to which an innovation is seen as consistent with existing experiences, needs, and beliefs of adopters;

3) Complexity: the degree of how difficult the innovation is to understand and use;

4) Trialability: the degree to which the innovation may be used on a limited basis;

5) Observability: the degree to which the results of an innovation are visible to others.

The third stage is the decision made by individuals to accept or reject the technology. The fourth stage is the implementation of this new technology and the finally stage confirms the decision made by the individual.

According to the definition of [17], adoption is the integration of a new technology ${ }^{2}$ into existing practice and is usually proceeded by a period of "trying" and some degree of adaptation. [18] defines adoption as a mental process an individual pass from first hearing about an innovation to final utilization of it. It has two categories: rate of adoption and intensity of adoption. The former is the relative speed with which farmers adopt an innovation, has as one of its pillars,

\footnotetext{
${ }^{2}$ Technology is the means and methods of producing goods and services, including methods of organization as well as physical technique (Loevinsohn et al., 2013). It is the knowledge or information that permits some tasks to be accomplished more easily, some service to be rendered or the manufacture of a product (Lavison, 2013).
} 
the element of time. While, intensity of adoption refers to the level of use of a given technology in any time period.

Technology adoption is a complicated task since it varies with the technology being adopted. Therefore, in defining agricultural technology ${ }^{3}$ adoption by the farmers, the first thing to consider is whether adoption is a discrete state with binary response variables or not [7]. That means definition depends on the fact that the farmer is an adopter of the technologies or non-adopter taking values zero and one or the response is continuous variable [19]. Agricultural new technologies constitute the introduction and use of hybrids, the greenhouse technology, genetically modified food, chemical fertilizers, insecticides, tractors and the application of another scientific knowledge. [20,16] briefly explains technology adoption level in to five steps as innovators (2.5\%), early adopters (13.5\%), early majority (34\%), late majority (34\%) and laggards (16\%). Agricultural new technologies are the factors of production which have undergone some form of amendment from their original state with the intent of enhancing their performance.

\subsection{Determining factors of Agricultural technology Adoption}

This paper deeply reviews the major determining factors which influences agricultural technology adoption in five parts, i.e., economic, technological, demographic, socio-cultural, and institutional factors.

\subsubsection{Economic factors}

Farm size plays a critical role in adoption process of a new technology. Many authors have analyzed farm size as one of important determinant factors influencing technology adoption. Farm size can affect and in turn be affected by the other factors influencing adoption. Different studies that were done on the impact of farm size on adoption of improved agricultural technology revealed the contradicting results. But many studies have reported a positive relation between farm size and adoption of agricultural technology [21, 22]. According to [23], farmers with a large farm size are likely to adopt a new technology as they can afford to devote part of their land to try new technology. While farmers with small land size adopt technologies, which is not consume large land such as greenhouse technology, zero grazing among others as an alternative to increased agricultural production. Reviewer agrees with that, a farmer with large farm size has better probability to adopt the improved agricultural technology than the farmers who has small land.

Family size is simply used as a measure of labor availability. It determines adoption process in that, a larger household have the capacity to relax the labor constraints required during introduction of new technology [18, 24]. According to [25], household size has to be positive and significant at $1 \%$ significance level in which each additional of family size increases the probability of adoption of improved maize varieties by 5.85 percent.

The cost of adopting agricultural technology is also the critical factors for technology adoption. As the study done by [26] on determinants of fertilizer and manure use in maize production in Kiambu county, Kenya; reported high cost of labor and other inputs, unavailability of demanded packages and untimely delivery as the main constraints to fertilizer adoption. The study done by [3], revealed that the elimination of subsidies on prices of seed and fertilizers since the 1990s due to the World Bank-sponsored structural adjustment programs in sub-Saharan Africa has widened this constraint. Among other factors constraining adoption of fertilizer and hybrid seed in Embu county Kenya, cost of hired labor was one among them [27].

Many studies on off-farm income reported a positive impact on technology adoption. According to [12], off-farm income is an important strategy for solving credit constraints faced by the rural households in many developing countries. As $[28,29]$ reported off-farm income act as a substitute for borrowed capital in rural economies where credit markets are either missing or dysfunctional.

Tropical Livestock Unit (TLU) is also another determinant factors which affect the adoption of improved agricultural technology in developing countries. The extent of livestock ownership significantly and positively affected adoption and intensity of use of improved technologies. The study of $[30,23]$ reported that better risk bearing behavior of those wealthy farmers with better livestock would enable them to try those newly adapted technologies.

\subsubsection{Technological factors}

The farmers' decision of whether or not to adopt a given new technology is based on a careful evaluation of many factors. Among these, the nature or the characteristics of technology is the foremost factors for adoption of improved agricultural technology. A degree at which a probable adopter can give a trial on a small scale first before accepting it from beginning to the end is a major determinant of technology adoption [7]. The features of the technology are the reasons for adopting Imazapyr-Resistant maize (IRM) technology in Western Kenya, which plays a critical role in the adoption decision process [24]. If the technology is very complex and difficult to operate, it cannot attract the farmers to adopt it. Further, if the technology is divisible like high yielding variety, fertilizer, herbicides, pesticides and the likes, the farmers are able to try out the innovation on a small scale and will be willing to adopt but if it is lumpy, small scale trials are not possible and the farmer may be more reluctant to adopt.

\footnotetext{
${ }^{3}$ Agricultural technology is the scientific methods, tools and machinery that are used primarily or entirely in order to support and modernize agricultural sector and to bring required changes in the sector.
} 
According to [24] study on Imazapyr-Resistant maize technology in Western Kenya, the characteristic of the technology plays a critical role in adoption decision process. They argued that farmers who perceive the technology being consistent with their needs and compatible to their environment are likely to adopt since they find it as a positive investment. Farmers' perception about the performance of the technologies significantly influences their decision to adopt them. Farmers' perception on the characteristic of modern rice variety significantly influenced their decision to adopt it [31].

\subsubsection{Demographic factors}

Farmers' age, gender and educational status are likely influence the probability of farmers' adoption of new technology [32]. Gender is a very important explanatory variable in studying factors of adoption. The prevailing social set up of rural households placed a varying responsibility among male and female members. Many studies revealed that being women headed negatively influencing technology adoption decisions. Due to social and cultural values and norms, males have the freedom to mobility, to attend in different training, meetings and workshops.

According to [4], sex of the household head was found negatively influencing adoption of the technology. It revealed that if the household head is male, the chances of adoption of wheat technology package decreases. Contrary to this finding, [33, 7] found that male-headed households were found to be more likely to adopt improved wheat varieties than female headed. As [34] reported that being male-headed household has a positive and significant relationship (at 5\% level) with the probability of adoption of improved maize variety. Male-headed households tend to adopt the varieties more than their female counterparts due to relatively better access of male-headed households to information and agricultural resources than female household heads. Those male headed households who have more access to information to use innovation than female-headed households, which have a capacity to influenced by the cultural norms and traditions. The Reviewer agree with that, especially in developing countries, male-headed households has better access to participate in training, workshop and has better exposures to information which helps to adopt the improved technology more easily than female-headed households.

Age of the household heads plays an important role in farmers' technology adoption behavior. Different agricultural technology adoption studies reported different conflicting ideas. Some findings confirmed that age negatively influencing adoption behavior of farmers. On the other hand, other studies confirmed that age positively affected adoption of improved agricultural technology. According to [24], age is assumed to be a determinant factor of adoption of new technology. Older farmers are assumed to have gained knowledge and experience over time and are better able to evaluate technology information than younger farmers. On contrary age has been found to have a negative relationship with adoption of technology. When farmers grow older, there is an increase in risk aversion and a decreased interest in long term investment in the farm. On the other hand, younger farmers are typically less risk-averse and are more willing to try new technologies [31,35]. But the reviewer supports the argument if age has a negative relationship with adoption of agricultural new technologies. Younger generations are more eager to practice modern technologies on their farm than older generation. This is due to younger farmers has more access to information and they are characterized as innovative which enables them to make decision on adoption of agricultural new technologies.

Education status of the household head is the most common and very important variable that is found to explain farmer's agricultural technology adoption behavior. Various studies confirmed that it has a significant positive influence on adoption of technologies. [36] studied factors affecting adoption of improved sorghum varieties in Somali region of Ethiopia and found out that more educated farmers are more likely to adopt improved sorghum varieties. [37] also reported similar results as educated farmers are better able to process information and search for appropriate technologies to alleviate their production constraints.

\subsubsection{Socio-Cultural factors}

Cultural differences/traits enter into the agricultural technological adoption process through network formation, indirect effects such as imitation, peer effects, and norm-based diffusion. Imitation describes the process in which farmers adopt simply because others are adopting, not because they are making a cost-benefit decision. According to [38], being whether religion and clan membership affect the likelihood of adopting pineapple farming in Ghana. Cultural differences have a great influence on technology adoption and diffusion because of some technology may not be acceptable in some cultural zones/society and while it will be acceptable in other cultural zones.

Participation in social groups and farmers research group (FRG ${ }^{4}$ ) has a great influence on adoption of improved agricultural technology. Farmers who participate in different social activity and farmers research group have better information about the technology which in turn enhances the adoption of the technology. Actively participating farmers

\footnotetext{
${ }^{4}$ Farmers Research Group is one of the participatory agricultural research approaches aimed to improve the conventional top-down research approach that doesn't fully address the needs of subsistence and smallholder farmers. It has a research approach by which a multi-disciplinary research team, extension workers and groups of farmers jointly conduct participatory on-farm agricultural research through need-based technology generation, adaptation and dissemination.
} 
in farmers research group and giving them the chance to involve in demonstration researches, improves the overall awareness of farmers toward the technology adoption and well equips them to look forward regarding the advantage of the new technologies over the existing one [39, 9].

\subsubsection{Institutional Factors}

Access to extension service helps to spread information and farmers to get updated information regarding agricultural technologies which helps them to adopt the new technologies easily. Many authors have reported a positive relationship between extension services and technology adoption. Close contact of farmers with extension agents increase the farmers' awareness toward improved agricultural technology and which in turn enhances the adoption. Farmers are usually informed about the existence as well as the effective use and benefit of new technology through extension agents. Extension agent acts as a link between the innovators (Researchers) of the technology and users of that technology. This helps to reduce transaction cost incurred when passing the information on the new technology to a large heterogeneous population of farmers [40]. In fact, the influence of extension agents can counter balance the negative effect of lack of years of formal education in the overall decision to adopt some technologies [18]. The study of [6] reported that contact with extension workers positively affects adoption of chemical fertilizer and statistically significant. Farmers who are visited by extension agents, keeping other things constant, have $11.1 \%$ higher probability of adopting, chemical fertilizer unlike non-visited or non-contacted farmers in northern parts of Ethiopia.

Access to credit is very critical factor to adoption of agricultural technology by the smallholders. It can facilitate farm households to purchase the needed agricultural inputs and enhance their capacity to effect long term investment in their farms. According to [6], access to credit is one of the best option whereby smallholders could be instigated in diversifying their economic base and it is statistically significant in determining the adoption decision of chemical fertilizer and high yielding variety (HYV) in northern Ethiopia. Farm households who has credit access, keeping other things constant, have $9.9 \%$ and $24.5 \%$ higher probability of adopting chemical fertilizer and HYV, unlike the credit rationed farmers respectively.

Information Access about a new technology is another factor that determines technology adoption. It enables farmers to learn the effective use of technology and this facilitates adoption. Farmers will only adopt the technology they are aware of or have heard about it. Access to information reduces the uncertainty about a technology's performance hence may change individual's assessment from purely subjective to objective over time [18]. It means that farmers may perceive the technology and subjectively evaluate it differently than scientists [41]. Sometimes access to information may also result to dis-adoption of the technology. For instance, where experience within the general population about a specific technology is limited, more information induces negative attitudes towards its adoption, probably because more information exposes an even bigger information vacuum hence increasing the risk associated with it [18]. It is therefore important to ensure the information is reliable, consistent and accurate. The reviewer agrees with access to information enhances the adoption of improved agricultural technology.

Access to road, distance to the nearest market and farmers training center is an important factor which determine the technology adoption. When there is access to roads which connects rural farmers with market, they can easily transport what they produce to the market. If the market linkage is increased, which in turn increases the farmers' confidence to produce demand-based commodity for sale through using improved agricultural technology. According to [33], distance from market negatively influenced adoption of wheat technology package. The result indicates that a kilometer increase in distance from market leads to a decrease in the likelihood of adoption of wheat technology packages by a factor of 0.023, other factors kept constant. As [39, 42] results revealed that farmers who are located far from the farmers' training center, they have less likely to adopt improved agricultural technologies. This might be due limited access to new information concerning technologies and lower probability of those farmers to be involved in on-farm research trials and visits.

Access to Irrigation is also the main factor which likely influences the adoption of agricultural technologies. Many studies reported the significant influence of irrigation water access to the agricultural technology adoption. As [6] reported in his study, presence of irrigation practices and irrigation use was found to be statistically significant in determining adoption of chemical fertilizer and HYV, respectively, at 5 and $1 \%$ significance level. Farmers who has an irrigable land and who use irrigation water, keeping other things constant, have $9.8 \%$ and $23.6 \%$ higher probability of adopting chemical fertilizer and HYV unlike their counter parts respectively. If there is no access to irrigation and there is erratic rainfall, the adoption of technology by farmers fail under question. If the farmers get irrigation access, their probability of adopting the intended technology found to be high.

\subsection{Conceptual Framework of Adoption of Improved Agricultural new technologies}

Improved agricultural technology adoption was influenced by many factors. Social, economic, institutional and technological factors are the most cited factors which influences the adoption of the improved agricultural technology. The most important variables included in this review is farm size, family size, off-farm income, TLU, gender, 
educational status, access to extension, access to irrigation, access to market and social and cultural traits. Some variables affect the probability of adopting the technologies more than other factors in specific areas and on specific technologies. If the technology is very complex and difficult to operate and apply, the farmers cannot be voluntary to easily accept it rather they prefer divisible technologies like high yielding varieties and fertilizer [24]. The farmers with large farms are likely to adopt a new technology as they can afford to devote part of their land to try new technology than the farmers who has small land [23]. Also, farmers who live around farmers training center are likely to adopt the technology than who lives far from the center [42].

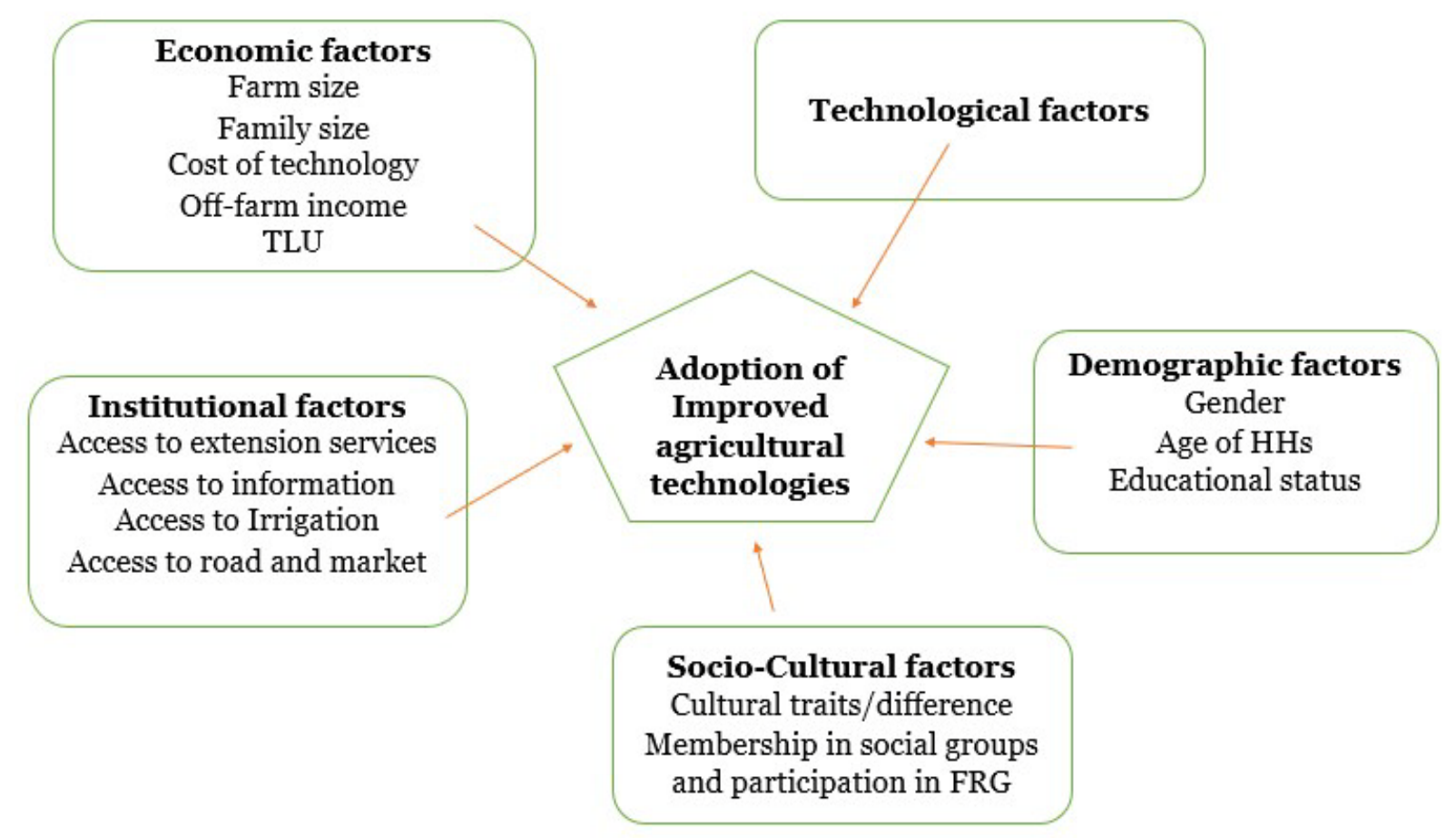

Figure 1. Conceptual framework.

\section{Summary}

Adoption of improved agricultural technologies is the foremost tools from the review, it was obtained that technological, socio-cultural, demographic, economic and institutional factors are the main determinant factors which hinders the rate and intensity of technology adoption. The farmers' perception toward the nature/characteristics of the technology is a pre-condition for their decision. Individual decision whether to adopt the technology or not depends on five attributes; relative importance of the new technology over the existing one, the degree of compatibility, the degree of complexity, trialability, and observability. As the review revealed that, the effect of the variable varies depending on the nature and cost of technologies, educational status of the individual and its exposures to different accesses. For instance, age as a determinant factor of adoption, many scholars reported contradicting ideas on it. Some scholars said when farmers grow older, there is an increase in risk aversion and has decreased interest in long term investment in the farm than younger farmers. On the other hand, some other scholar reported that they adopt more easily than younger farmers due to the information and experience they obtained through time. Knowing the determinant factors of agricultural technology adoption and incorporating farmers preference criteria and need is very crucial points for policy makers and agricultural technology developer to overcome the low adoption rate problems and in turn for boosting production and productivity, food self-sufficiency and ensuring food security in developing countries.

\section{Conflict of Interest}

There is no conflict of interest.

\section{References}

[1] Wekesa, E., W. Mwangi, H. Verkuijl, K. Danda, and H. De Groote. (2003). Adoption of maize production technologies in the coastal lowlands of Kenya. Mexico, D.F.: CIMMYT WB. (2008). The Growth Report: Strategies for Sustained Growth and 
Inclusive Development. Washington D.C., Commission on Growth and Development, World Bank or The International Bank for Reconstruction and Development/The World Bank.

[2] Wondimagegn, M., Bekabil, F., \& Jema, H. (2011). Pattern, Trend and Determinants of Crop Diversification: Empirical Evidence from Smallholders in Eastern Ethiopia. Journal of Economics and Sustainable Development Vol.2, No.8, 2011.

[3] Muzari W., Wirmayi G., Shepherd M., (2012). The impact of technology adoption on smallholder agricultural productivity in Sub-saharan Africa. Review article. Journal of Sustainable development. Vol. 5, No. 8.

[4] Asfaw S, Shiferaw B, Simtowe F, Lipper L. (2012). Impact of modern agricultural technologies on smallholder welfare: Evidence from Tanzania and Ethiopia. Food Policy 37: 283-295.

[5] Besley, T., \& Case, A. (1993). “Modeling Technology Adoption in Developing Countries.”The American Economic Review 83: 396-402.

[6] B Kassa, B. Kassa and K. Aregawi. (2014). Adoption and impacts of agricultural technologies on farm income: evidences from southern Tigray, Ethiopia. International Journal of Foodand Agricultural Economics pp. 91-106.

[7] Doss, C. R., \& Morris, M. L. (2001). "How Does Gender Affect the Adoption of Agricultural Innovations? The Case of Improved Maize Technology in Ghana.”Agricultural Policy 25: 27-39.

[8] Foster, D., and Rosenzweig, M. (1995). "Learning by Doing and Learning from Others: Human Capital and Technical Change in Agriculture.” Journal of Political Economy 103 (6): 1176-1209.

[9] Shiferaw B. A, Okello J, Reddy R. V. (2009). Adoption and adaptation of natural resource management innovations in smallholder agriculture: reflections on key lessons and best practices. Environment, Development and Sustainability 11: 601-619.

[10] Datt, G., \& Ravallion, M. (1996). How Important to India’s Poor is the Sectoral composition of Growth? World Bank Economic Review 10(1), 1-26.

[11] Kassie, M., Jaleta, M., Shiferaw, B., Mmbando, F., \& Mekuria, M. (2013). Adoption of interrelated sustainable agricultural practices in smallholder systems: Evidence from rural Tanzania. Technological forecasting and social change, 80(3), 525-540.

[12] Ravallion, M., \& Chen, S. (2004). “How have the world’s poorest fared since the early 1980s?” World Bank Research Observer, 19 (2): 141-170.

[13] Kohli, I., Singh, N. (1998). "Exports and Growth: Critical minimum effort and diminishing returns.” Journal of Development Economics. 1 (30): 391-400.

[14] Bandiera, O., and Rasul, I. (2002). Social Networks and Technology Adoption in Northern Mozambique. Discussion Paper Series. London, UK, Centre for Economic Policy Research CEPR. April 2002.

[15] Sahar N. Ssewanyana and Ibrahim Kasirye. (2010). Food security in Uganda: achieving the millennium development goal. DOI: 10.22004/ag.econ.113614.

[16] Rogers, E. M. (2003). Diffusion of innovations. Free Press. New York, 551.

[17] Loevinsohn M, Sumberg J, Diagne A. (2012). Under what circumstances and conditions does adoption of technology result in increased agricultural productivity? Protocol. London: EPPI Centre, Social Science Research Unit, Institute of Education, University of London.

[18] Bonabana-Wabbi J. (2002). Assessing Factors Affecting Adoption of Agricultural Technologies: The Case of Integrated Pest Management (IPM) in Kumi District, Msc. Thesis Eastern Uganda.

[19] Challa, Merga. (2013). Determining Factors and Impacts of Modern Agricultural Technology Adoption in West Wollega, Munich, GRIN Publishing GmbH, http://www.grin.com/en/e-book/280336/determiningfactors-and-impactsof-modern-agricultural-technology-adoption.

[20] Rogers, Everett M. (1962). Diffusion of Innovations. Glencoe: Free Press. ISBN0612628434.

[21] Ahmed S. (2004). Factors and Constraints for Adopting New Agricultural Technology in Assam With Special Reference to Nalbari District: An Empirical Study. Journal of Contemporary Indian Policy.

[22] Gabre-Madhin, Z. and Haggblade, S. (2001). Success in African Agriculture: Results of an Expert Survey. International Food Policy Research Institute. Washington DC. June 2001.

[23] Solomon Y, Endrias O. (2018). Participatory Demonstration of Maize (Zea Mays L.) Variety with its Full Packages in South Ethiopia. Adv Crop Sci Tech 6: 342. doi:10.4172/2329-8863.1000342.

[24] Mignouna, B., Manyong, M., Rusike, J., Mutabazi, S., \& Senkondo, M. (2011). Determinants of Adopting Imazapyr-Resistant Maize Technology and its Impact on Household Income in Western Kenya: AgBioforum, 14(3), 158-163.

[25] Alemayehu Keba. (2019). Adoption of improved maize varieties: the case of Kiremu district, Oromia regional state, Ethiopia, Master thesis submitted to Jimma University.

[26] Makokha, S., Kimani, S., Mwangi, W., Verkuijl, H., Musembi, F. (2001). Determinants of Fertilizer and Manure Use for Maize Production in Kiambu District, Kenya. CIMMYT (International Maize and Wheat Improvement Center) Mexico.

[27] Ouma, J., Murithi,F., Mwangi, W., Verkuijl, H., Gethi M, De Groote, H. (2002). Adoption of Maize Seed and Fertilizer 
Technologies in Embu District, Kenya. CIMMYT (International Maize and Wheat Improvement Center), Mexico, D.F.

[28] Diiro, G. (2013). Impact of Off-farm Income on Technology Adoption Intensity and Productivity: Evidencefrom Rural Maize Farmers in Uganda. International Food Policy Research Institute, Working Paper.

[29] Ellis, F. and Freeman, H. Ade, H. (2004). "Rural Livelihoods and Poverty Reduction Strategies in Four African Countries." Journal of Development Studies 40(4): 1-30.

[30] Haji Biru. (2003). Adoption of crossbred dairy cows in Aris Zone, The case of Tiyo and Lemu Bilbilo Woreda. M.Sc Thesis presented to School of Graduate Studies of Haramaya University.

[31] Adesina, A., \& Zinnah, M. (1993). Technology characteristics, farmers’ perceptions and adoption decisions: a Tobit model analysis in Sierra Leone. Agricultural Economics.

[32] Mamudu. A., Emelia. Guo., Samuel, K. (2012). Adoption of Modern Agricultural Production Technologies by Farm Households in Ghana: What Factors Influence their Decisions? Journal of IISTEbiology, agriculture and healthcare 2(3).

[33] Degefu Kebede, Mengistu Ketema, Nigussie Dechassa, Feyisa Hundessa. (2017). Determinants of adoption of wheat production technology packages by smallholder farmers: Evidences from eastern Ethiopia.Turkish Journal of Agriculture-Food Science and Technology, 5(3): 267-274.

[34] Gishu Nigatu. (2018). "Determinants of Adoption of Improved (BH-140) Maize Variety and Management Practice, in the Case of South Ari, Woreda, South Omo Zone, SNNPRS, Ethiopia”, International Journal of Research Studies in Biosciences (IJRSB), vol. 6, no. 9, pp. 35-43, 2018. http://dx.doi. org/10.20431/2349-0365.0609004.

[35] Mauceri, M., Alwang, J., Norton, G. Barrera, V. (2005). Adoption of Integrated Pest Management Technologies: A Case Study of Potato Farmers in Carchi, Ecuador; Selected Paper prepared for presentation the American Agricultural Economics Association Annual Meeting, Providence, Rhode Island, July 24-27, 2005.

[36] Mahdi Egge, P. Tongdeelert, S. Rangsipaht and S. Tudsri. (2012). Factors affecting the adoption of improved sorghum varieties in awbare district of somali regional state, Ethiopia. Kasetsart J. (Soc. Sci). 33: 152 -160.

[37] Alemitu Mulugeta. (2012). Factors affecting adoption of improved haricot bean varieties and associated agronomic practices in Dale Woreda, SNNPR.MSc thesis submitted o Hawassa University.

[38] Lee K. (2011). The Role of Culture in Agricultural Technology Diffusion in Ghana. Unpublished MMSS Senior thesis, Department of Economics.

[39] Alemitu Mulugeta. (2012). Factors affecting adoption of improved haricot bean varieties and associated agronomic practices in Dale Woreda, SNNPR.MSc thesis submitted o Hawassa University.

[40] Genius, M., Koundouri, M., Nauges, C and Tzouvelekas, V. (2010). Information Transmission in Irrigation Technology Adoption and Diffusion: Social Learning, Extension Services and Spatial Effects.

[41] Tesfaye Zegeye and Alemu Haileye. (2001). Adoption of improved maize technologies and inorganic fertilizer in Northwestern Ethiopia. Ethiopian Agricultural Research Organization (EARO). Research report No.40, Addis Ababa, Ethiopia. p. 51.

[42] Yanggen, D., Kelly, V., Reardon, T., \& Naseem, A. (1998). Incentives for Fertilizer Use in Sub-Saharan Africa: A Review of Empirical Evidence on Fertilizer Response and Profitability. MSU International Development Working Papers no. 70 ISSN 0731-343. 